\title{
Effect of Modern Gadgets in Enhancing the Academic Skills of Young Learners
}

\author{
N. Mathankumar, M. Sankar, S. Janifer Vinnarasi
}

\begin{abstract}
Data Systems (IS) usage in advanced education is a huge speculation. Such ventures are required to bring expanded productivity and viability, just as better quality administrations to partners. Our writing search didn't discover understudy data the board frameworks (SIMS) in Ethiopia or comparative low-salary nations. This examination is work in progress. It endeavors to connect the writing hole for use and achievement variables of SIMS in a college setting of low salary nations. The examination will address the exploration question: what determinant elements add to the achievement or disappointment of IS in advanced education establishments in Ethiopia, with specific reference to SIMS? The examination utilizes DeLone and McLean(1992, 2003) IS Success Model to recognize the elements of IS achievement when applied to SIMS. We additionally examine two new develops top administration backing and client bolster that were discovered applicable in the examination setting.
\end{abstract}

Keywords : Student information management system, higher education institutions, IS Success Model, information quality, systemquality, user support, top management support.

\section{INTRODUCTION}

Information system is defined as a 'collection of subsystems defined by functional or organizational boundaries (Iivari,1991). It supports decision-making and control in organizations (Lucas, 1981) by utilizing information technology to capture, transmit, store, retrieve, manipulate, or display information used in one or more business processes' (Alter, 1996).Like any modern business sector, Higher Education Institutions (abbreviated as HEIs) need to achieve and enhance quality inits functioning. But these institutions face challenges in the process of attaining the objective of becoming better quality HEI.McClea and Yen, (2005) stated that:"In this sector the challenge begins with the institution's admission department. The admissions department functions as the delivery point for quality inputs, which should eventually become even higher quality outputs[1]-[3]. The department, then, must collect significant amounts of data about students as well as maintain the ability to effectively analyze and transform the

Revised Manuscript Received on December 16, 2019

N. Mathankumar, Department of Science and Humanities, Bharath Institute of Higher Education and Research, Chennai, India. Email: ma.aswinkumar18@gmail.com

M. Sankar, Department of Science and Humanities, Bharath Institute of Higher Education and Research, Chennai, India. Email: sankar06.phd@gmail.com

S. Janifer Vinnarasi, Department of Science and Humanities, Bharath Institute of Higher Education and Research, Chennai, India. Email: mjjaa24@gmail.com data into pertinent information. This develops a new function for the admission department to perform - information technology. Information technology presently represents a critical success factor for numerous organizations. Higher educational institutions fall into this category and have sought the status of first movers in relation to the development and implementation of information technology throughout the areas of academia" (McClea and Yen, 2005).

The paper is organized in four sections. The first section develops the basis for the case study by introducing St. Mary'sUniversity College and its SIMS. The second section deals with the theoretical framework to be used in investigating the success or failure of SIMS. This section will present the DeLone and McLean (1992) information system success model, additional constructs to be added in the model which are determinant factors for the IS success in our context, definition of each construct and the hypothesis set for each of the constructs[4]-[5]. The third section presents the methodology to be followed in studying the IS success factors. In this section the method to be applied, measurement instruments, and sample size as well as data collection techniques will be discussed. In the last section we present our concluding remarks and indicate the expected results and contributions of the study.

\section{A. Conceptual Model}

$$
\text { Individual Impact }
$$
Organizational Impact

\section{MOTIVATION AND STUDY BACKGROUND}

Investment in the area of SIMS is a high priority in the case of Ethiopian HEIs. This is mainly because of the recent trend of expansion of HEIs and increase in student enrollment. As recently as the year 2005, there were only 9 public HEIs in Ethiopia. In the last three to four years 13 new public universities were built and made operational, raising the number of public HEIs to 22. In addition to this about 250 private higher education institutions have been established in the past ten years, most of which offer diploma and certificate programs[6]-[7]. About 55 of the 250 private higher education institutions offer degree programs and 2 of the 250 offer post graduate programs. Therefore, a total of 263 new public and private higher education institutions have been

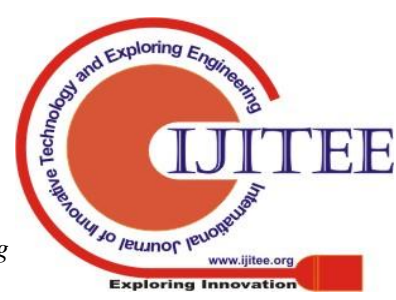


established in the past ten years. This increased the total number of both public and private HEIs to 272. Partly because of this expansion, the average five year growth in tertiary level enrollment reached $27 \%$. This expansion brought significant increase in student enrollment. In order to cope up with such expansions in student enrollment, institutions of higher education are making investment in the development and implementation of IS and it is a most recent phenomenon in the case of Ethiopia. Appropriate evaluation of these systems remains an important agenda for higher education management if they are to see a good return for their costly investment. Thus, our motivation is to conduct this study to help identify determinant factors that contribute to the success or failure of IS implementation and use in HEIs with particular reference to SIMS in Ethiopia using a specific case. We selected St. Mary's University College mainly because of the experiences one of the co-authors as a staff member at the university college during its system development and implementation. Currently the researcher is also a primary user of the system.

St. Mary's University College is a private HEI which was established in the year 2000. It is one of the two private higher education institutions that offer post graduate programs. It also offers degree, diploma and certificate programs in conventional mode (Regular and Extension face-to-face classes) as well as in distance education mode. There are a total of 22 departments in both conventional and distance education mode that offer degree, diploma and certificate programs. The total number of students in both modes is 40,393 , of which 16,833 are degree students, with 20,545 diploma students and3,015 Certificate students in both conventional and distance programs. The total number of full time academic staff is 206, and that of administrative staff is 778.SIMS for the University College is developed in-house based on the requirement specification of the Registrar's Office[8]-[10]. The system is developed using PHP programming language with MySQL database. Apache Server is used to configure the system. After properly testing the SIMS it was implemented successfully in September 2008. The system supports functions including storing and processing students' admission data, handling course registration, scheduling classes, entering and processing grades, generating grade reports and transcripts, processing graduation related data and generating statistical reports of different kind for multiple purposes.

\section{THEORETICAL FRAMEWORK}

\section{A. Background on the Model}

Research in the course of recent decades has brought about various ways to deal with the assessment of IS achievement. Some of them incorporate framework use, Information Value, client fulfillment and all the more as of late help quality. Such fluctuated ways to deal with IS achievement measures recommend absence of understanding in regards to the topic of what establishes IS achievement. One of the normally refered to papers in the writing is that of DeLone and McLean (1992). In their paper, the creators combined
100 exact IS achievement measures (distributed somewhere in the range of 1981 and 1987) and proposed a model that fuses a few individual elements of accomplishment into a general model of IS achievement. DeLone and McLean presented six significant measurements or classifications of ISsuccess - framework quality, data quality, use, client fulfillment, singular effect and hierarchical impact.According to DeLone and McLean (2003), in the IS Success Model, "frameworks quality" measures specialized success;"information quality" measures semantic achievement; and "use, client fulfillment, singular effects," and "authoritative effects" measure viability achievement[11]-[13]. As they have expounded, an is first made, containing different highlights, which can be described as showing different degrees of framework and data quality. Next, clients and supervisors experience these highlights by utilizing the framework and are either fulfilled or disappointed with the framework or its data items. The utilization of the framework and its data items at that point effects or impacts the individual client in the lead of their work,and these individual effects all things considered outcome in authoritative effects. As per Gable et al. (2003), the develops/proportions of the Delone and McLean model gave an all encompassing perspective over the association-from a top the executives viewpoint, to that of information passage officials' - and gave a point by point order of accomplishment measurements.

\section{B. Construct Definition and Hypothesis}

Framework quality is a proportion of the data handling framework itself. Most measures in this class tap engineering oriented performance qualities. It comprises of execution attributes of the frameworks which incorporate resource utilization, dependability, reaction time, simplicity of terminal use, information precision, unwavering quality, fulfillment, framework adaptability and ease of use. In the instance of Student Information Management System, convenience, reaction time, correspondence without breaking a sweat of learning are the significant characteristics that are esteemed by clients of the Student Information Management System. Seddon and Kiew (1994) found in their way investigation that data quality and framework quality are significant determinants of by and large client fulfillment. The Technology Acceptance Model (Davis et al., 1989) predicts that apparent straightforwardness of utilization, as a part of framework quality (DeLone and McLean, 1992) is a noteworthy immediate and aberrant determinant of utilization, the indirect impact being directed through apparent handiness. It is normal accordingly, that the higher the framework quality, the better the achievement of Student Information Management System (SIMS) as far as improved use and client fulfillment. This is spoken to by the accompanying theory.

Clients will no doubt look for help in utilizing the frameworks in their day by day activities. In view of the confirmations, it is conceivable to hypothesize the connection between client support and IS accomplishment as pursues[14]-[15]:

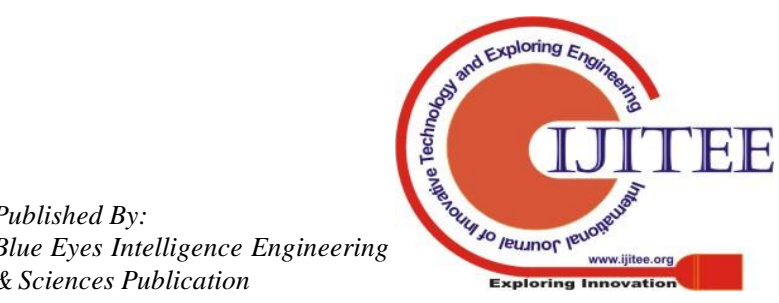


Offices, coordination focuses). Some of client fulfillment qualities which are important to the study are generally speaking fulfillment level, degree of reliance on the framework, expanded status of representatives, individual benefits gained, affirmation of convenience of the framework.

Baroudi et al., (1986) propose that if client fulfillment is translated as a frame of mind, the Theory of Reasoned Action (Fishbeinand Ajzen, 1975, refered to in DeLone and McLean, 1992) underpins the model that client fulfillment will impact aims to use the framework and real use. It is normal that the level of client fulfillment can influence the measure of utilization of SIMS. In addition to this, since client fulfillment is an immediate precursor of individual effect factors the previous influences the latter. Therefore, in light of these connections we set up the accompanying speculations in connection to client fulfillment develop.

The individual effect measurement is characterized by DeLone and McLean (1992) as "the impact of data on the conduct of the beneficiary". A portion of the qualities which are considered as determinants of individual effect include: information understanding, learning, exact translation, data mindfulness, data review, issue distinguishing proof, decision effectiveness, improved singular profitability, and assignment execution[16]-[18]. Those qualities which are most pertinent to the study are execution related issues. According to Bokhari (2005), "The prime reason for bringing IS into an association is to improve individual decision-production execution as well as in general authoritative productivity and viability. The normal gains in wording of organizational objectives through IS usage and reception are worried about the achievement of the framework". In this way, the impact on singular execution ought to in the long run have some hierarchical effect. In this way, the conceivable hypotheses that can be assembled is the accompanying:

H7: The effect on singular execution will be identified with the hierarchical effects of SIMS[19]-[21]

\section{RESULTS AND DISCUSSIONS}

A review instrument will be utilized to assemble information to test the connections appeared in the examination model. Essential clients of the framework at the college school will be overviewed with the end goal of requesting their perspectives and appraisal of the framework being utilized[22]-[23]. The objective populace incorporates all staff individuals from the Registrar Office and Finance Office, the school personnel and the top the board of the college school. The all out number of respondents is relied upon to be292. Three corresponding strategies will be utilized for gathering essential information: poll, meet and direct perception of Student Information Management System and administrations. The inquiries are drawn from recently approved instruments and adjusted to the present investigation setting. Data on the instruments or measures is exhibited in Appendix A. The examination will utilize perceptual measures to catch information on IS achievement factors. Perceptual estimates are adequate measures in most overview inquire about. A five-point Likert scale will be utilized to speak to the reactions of the subjects[24]-[25].

\section{CONCLUSION}

The discoveries of this work in progress study will show the significance of IS achievement factors in deciding the effectiveness of SIMS applications in the advanced education condition. This paper will make four significant commitments. First, it offers understanding of estimating the achievement of IS with regards to advanced education organizations of low pay countries such as Ethiopia. Second, it demonstrates which variables can become predominant in the achievement of a framework, particularly when it is developed in-house. Third, the distinguishing proof of accomplishment elements will help the top the board to concentrate on these variables and make the essential mediations. Fourth, it will open an opportunity and exercises learned for further examine in the zone. In general, this will be both a hypothetical and viable commitment to the field of IS achievement when actualized in HEIs; in particular HEI in low pay nations may profit by the exercises learned. Since this is all the more a model structure study, separated of our future arrangement is to lead exact research to approve the builds exhibited in the model.

\section{REFERENCES}

1. Vasanthi, S. \& Rabiyathul Basariya, S. 2019, "Influence of value analysis and cross training in industry", International Journal of Engineering and Advanced Technology, vol. 8, no. 6, pp. 1810-1811.

2. Velvizhi, R., Sri Gowtham, S. \& Jeya Priya, D. 2019, "Examination of early feedbacks for effective product retailing on E-commerce websites", International Journal of Engineering and Advanced Technology, vol. 8, no. 6 Special Issue 2, pp. 703-706.

3. Anuradha, C., Pothumani, S. \& Kavitha, R. 2019, "A novel method towards E-commerce", International Journal of Engineering and Advanced Technology, vol. 8, no. 6 Special Issue 2, pp. 535-538.

4. Thomas, J. \& Rabiyathul Basariya, S. 2019, "A study on the issues of financial ratio analysis", Indian Journal of Public Health Research and Development, vol. 10, no. 3, pp. 1079-1081.

5. Ramachandran, S. \& Rabiyathul Basariya, S. 2019, "Online marketing study on customer satisfaction and relationship", Indian Journal of Public Health Research and Development, vol. 10, no. 3, pp. 1072-1078.

6. Priya, R., Vinothini, G. \& Cor Jesu, C.D. 2019, "The mentor-protégé relationship for professional growth", Journal of Advanced Research in Dynamical and Control Systems, vol. 11, no. 9 Special Issue, pp. 1110-1119.

7. Jannifer Rani, N., Bina Pani, S. \& Nimisha, N.S. 2019, "A study on money back polices available in LIC", Journal of Advanced Research in Dynamical and Control Systems, vol. 11, no. 9 Special Issue, pp. 833-839

8. Saillaja, V., Jhansi Rani, K. \& Catherine, R. 2019, "Global marketing management planning and organization", Journal of Advanced Research in Dynamical and Control Systems, vol. 11, no. 9 Special Issue, pp. 489-493.

9. Saillaja, V., Jhansi Rani, K. \& Catherine, R. 2019, "The new phase of marketing information system", Journal of Advanced Research in Dynamical and Control Systems, vol. 11, no. 9 Special Issue, pp. $482-488$.

10. Thoufiqulla \& Raju, D.V. 2019, "Perception of indian investor towards investment in mutual funds with special reference to mip funds", Journal of Advanced Research in Dynamical and Control Systems, vol. 11, no. 5, pp. 177-183.

11. Jasmine, K.R.M. \& Basariya, S.R. 2018, "A study on the customers benefits on mutual funds", International Journal of Civil Engineering and Technology, vol. 9 , no. 4, pp. 45-48.

12. Vasanthi, S. \& Basariya, S.R. 2019, "Pros and cons of on the job training versus off the job training", International Journal of Scientific and Technology Research, vol. 8, no. 10, pp. 671-674. 
13. Pavithra, J. \& Ganesan, M. 2016, "A study on awareness and impact of micro-financial schemes", International Journal of Applied Business and Economic Research, vol. 14, no. 8, pp. 5449-5460.

14. Pavithra, J., Dilli Babu, P. \& Ambuli, T.V. 2014, "A study on budgetary control at Maruti Service Masters, Chennai", International Journal of Applied Business and Economic Research, vol. 12, no. 2, pp. 151-161.

15. Gunaraja, T.M. \& Venkatrama Raju, D. 2018, "Determining factors of organisational climate with reference to leadership styles", International Journal of Mechanical Engineering and Technology, vol. 9, no. 9, pp. $1327-1332$

16. Gunaraja, T.M. \& Venkatrama Raju, D. 2018, "The role of job satisfaction and training of employees in determining organisational climate of a selected industry", International Journal of Civil Engineering and Technology, vol. 9, no. 8, pp. 1266-1269.

17. Aarathy, T.S. \& Raju, D.V. 2018, "Performance appraisal and its effects on employees with respect to it sector in Chennai city", International Journal of Civil Engineering and Technology, vol. 9, no. 6, pp. $1535-1538$

18. Aarathy, T.S. \& Raju, D.V. 2018, "Employee perception towards performance appraisal system in IT sector", International Journal of Mechanical Engineering and Technology, vol. 9, no. 5, pp. 131-135.

19. Porselvi, W., Jublee, D. \& Sivanesan, G. 2018, "A study on factor influencing adoption of technology and innovation in banking industry, tamilnadu, India", International Journal of Mechanical Engineering and Technology, vol. 9, no. 5, pp. 789-800.

20. Akessa, G.M. and Dhufera, A.G., 2015. Factors That Influences Students Academic Performance: A Case of Rift Valley University, Jimma, Ethiopia. Journal of Education and Practice, 6(22), pp.55-63.

21. Miller, G. and Shih, C.C., 1999. A faculty assessment of the academic rigor of on-and off-campus courses in agriculture. Journal of Agricultural Education, 40, pp.57-65.

22. Tsinidou, M., Gerogiannis, V. and Fitsilis, P., 2010. Evaluation of the factors that determine quality in higher education: an empirical study. Quality Assurance in education, 18(3), pp.227-244.

23. Farooq, M.S., Chaudhry, A.H., Shafiq, M. and Berhanu, G., 2011. Factors affecting students' quality of academic performance: a case of secondary school level. Journal of quality and technology management, 7(2), pp.1-14.

24. Fitsilis, P., Gerogiannis, V. and Anthopoulos, L., 2014. Ontologies for software project management: a review. Journal of Software Engineering and Applications, 7(13), p.1096.

25. Adams, J.D. and Jaffe, A.B., 1996. Bounding the effects of R\&D: an investigation using matched establishment-firm data(No. w5544). National bureau of economic research.

\section{AUTHORS PROFILE}

N. Mathankumar Assistant Professor, Department of Science and Humanities, Bharath Institute of Higher Education and Research, Chennai, India.

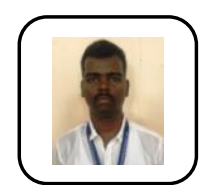

M. Sankar Assistant Professor, Department of Science and Humanities, Bharath Institute of Higher Education and Research, Chennai , India.

S. Janifer Vinnarasi Assistant Professor, Department of Science and Humanities, Bharath Institute of Higher Education and Research, Chennai , India. 